\title{
Aneurysmal Right Coronary Artery with Fistula to the Coronary Sinus: A Case Report
}

\author{
Saumya Sekhar Jenasamant, Shyamveer Singh, Manish Jawarkar, Tushar Kumar, \\ Harpreet Singh \\ G. B. Pant Institute of Postgraduate Medical Education and Research, New Delhi, India \\ Email:drshyam07@gmail.com, manishjawarkar@gmail.com,dr.tusharkumarpmch@gmail.com, mehtachitra@hotmail.com, \\ sekhar.ssjs@gmail.com
}

How to cite this paper: Jenasamant, S.S., Singh, S., Jawarkar, M., Kumar, T. and Singh, H. (2016) Aneurysmal Right Coronary Artery with Fistula to the Coronary Sinus: A Case Report. World Journal of Cardiovascular Surgery, 6, 177-184.

http://dx.doi.org/10.4236/wjcs.2016.612024

Received: November 24, 2016

Accepted: December 25, 2016

Published: December 28, 2016

Copyright $\odot 2016$ by authors and Scientific Research Publishing Inc. This work is licensed under the Creative Commons Attribution International License (CC BY 4.0).

http://creativecommons.org/licenses/by/4.0/

\begin{abstract}
Right coronary artery (RCA) communicating to coronary sinus (CS) resulting in aneurysmal dilatation of RCA is a rare congenital anomaly, usually presenting late with complication of left to right shunt and volume overload. We report a case of a 53 years old female presenting with dyspnea on exertion, orthopnea and angina. Echocardiography and computed tomography are suggestive of a fistulous communication of RCA to CS with aneurysm of RCA. Patient was treated surgically and is asymptomatic after three years of follow up.
\end{abstract}

\section{Keywords}

Coronary Arteriovenous Fistula, Aneurysmal RCA

\section{Introduction}

Coronary arteriovenous fistula is a rare congenital anomaly presenting in later life as an incidental finding or with major potential complications such as congestive heart failure, myocardial infarction, thrombosis, endocarditis, arrhythmia and even sudden death. The fistula results in shunting of blood from coronary artery to the draining cardiac chamber. The size of the fistula and the pressure difference between the coronary artery and the cardiac chamber determines the shunting of blood and its haemodynamic impact. Percutaneous closure of fistula is a method of treatment but surgery remains the best modality of management. The objective of reporting this case was to give emphasis on urgent surgical management which includes closure of fistulous opening and establishment of myocardial revascularization. 


\section{Case Report}

It was a 53 years old female who presented to us with complaints of gradual onset dyspnoea on exertion, orthopnoea and angina of NYHA grade II since 6 months. She had no other significant co-morbid illness. On examination her heart rate was $72 / \mathrm{min}$ and regular with a blood pressure of $110 / 60 \mathrm{mmHg}$. Physical examination showed a raised jugular venous pressure with slightly enlarged neck veins. There was no hepatomegaly, ascitis and peripheral limb edema. On auscultation chest was bilaterally clear with no associated cardiac murmurs.

Routine blood investigations were within normal limits. Chest X-ray showed cardiomegaly with a cardiothoracic ratio of 0.7 and mild pulmonary congestion. Electrocardiogram showed normal sinus rhythm without any evidence of strain pattern and chamber hypertrophy. 2D echocardiography revealed dilatation of right atrium and coronary sinus with a dilated right coronary artery communicating with coronary sinus. Colour Doppler showed a shunt flow from RCA to CS. Biventricular function was normal with normal valve morphology and no regional wall motion anomaly.

Computed tomography (CT) angiogram (Figure 1) was performed to delineate the complex anatomy and planning further management. CT (Figure 2) revealed a right coronary artery to CS fistula with markedly dilated and tortuous RCA running along the atrioventricular groove till the inferior wall of left ventricle. Left coronary artery was normal in anatomy and without any lesion. Conventional angiography (Figure 3 ) showed a fistula communicating between dilated RCA and CS. After complete assessment of the anatomy and physiology of the fistula and taking into consideration the symptomatic state of the patient a surgical correction was planned. Patient was explained about the rare incidence of the disease and its consequence if not treated. An informed consent was taken from the patient for surgery and for subsequent reporting of the case.

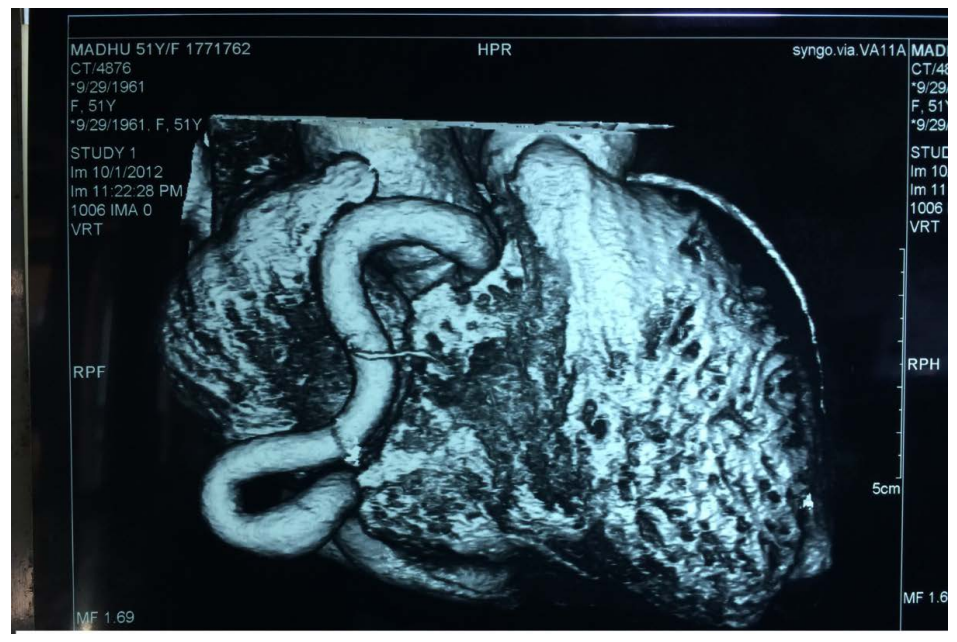

Figure 1. Computed tomography angiography showing dilated tortuous RCA. 


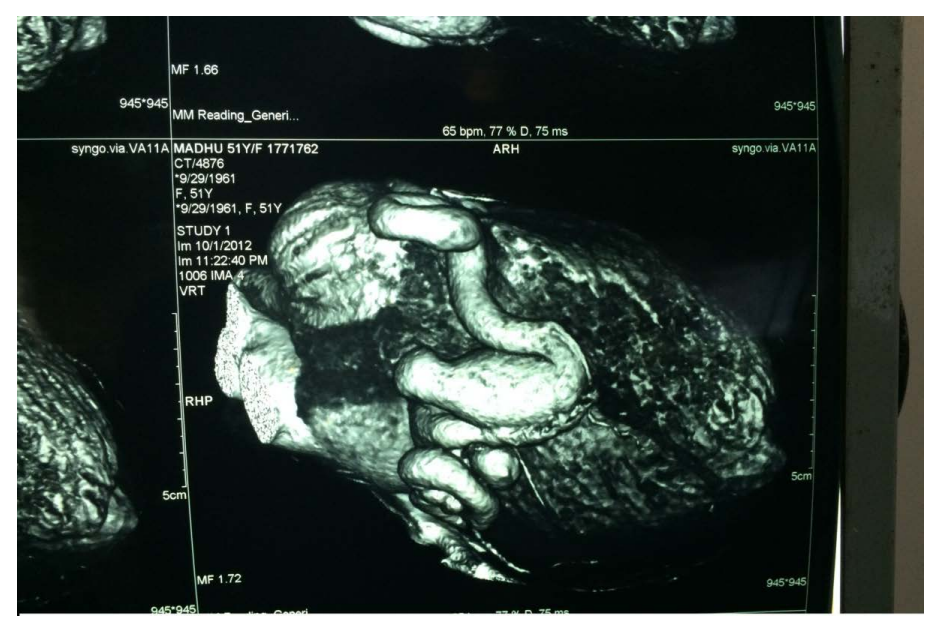

Figure 2. Computed tomography angiography showing dilated coronary sinus and RCA.

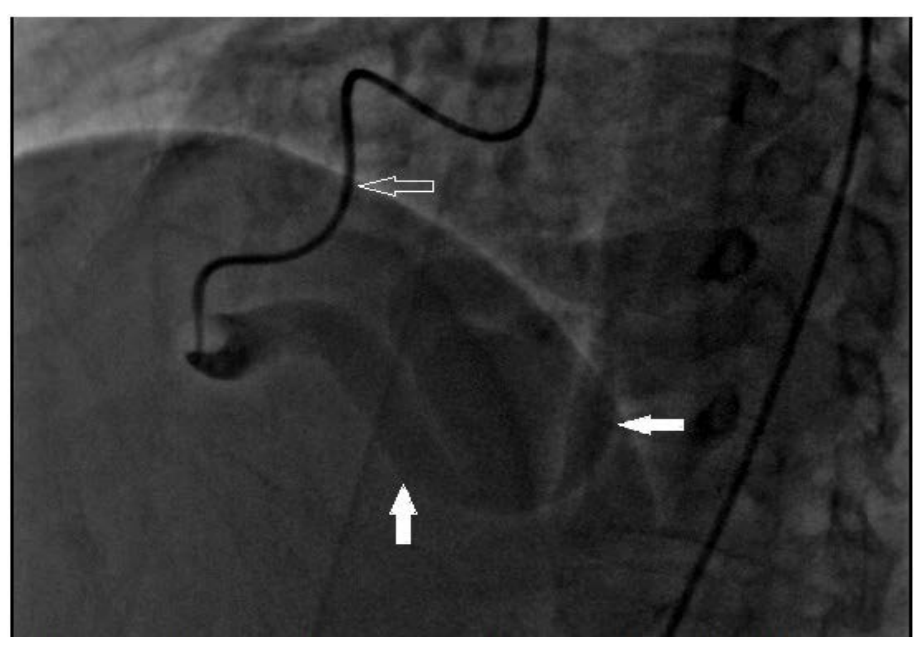

Figure 3. Conventional angiography. Solid arrow showing fistula and dilated CS. Hollow arrow showing catheter.

On Inspection after sternotomy a hugely dilated and tortuous RCA was found (Figure 4) running along the atrioventricular groove and continuing up to inferior wall of left ventricle. Coronary sinus (Figure 5) and right atrium were dilated, Right ventricle, Left atrium and Left ventricle were grossly normal. Patient was put on cardiopulmonary bypass with moderate hypothermic arrest. Right atrium was opened and the fistulous opening (Figure 6) in coronary sinus was identified and closed with sutures (Figure 7). Aorta was opened and the dilated right coronary ostium was closed with sutures. A venous graft was anastomosed to mid RCA from Aorta. Weaning from cardiopulmonary bypass was started but the patient developed severe right ventricular dysfunction and could not be weaned off from CPB. Insufficient revascularisation of RV was suspected. Therefore, the proximal dilated segment of RCA was excised and an $8 \mathrm{~mm} \mathrm{Da}$ cron Interposition graft was anastomosed between mid RCA and Ascending 


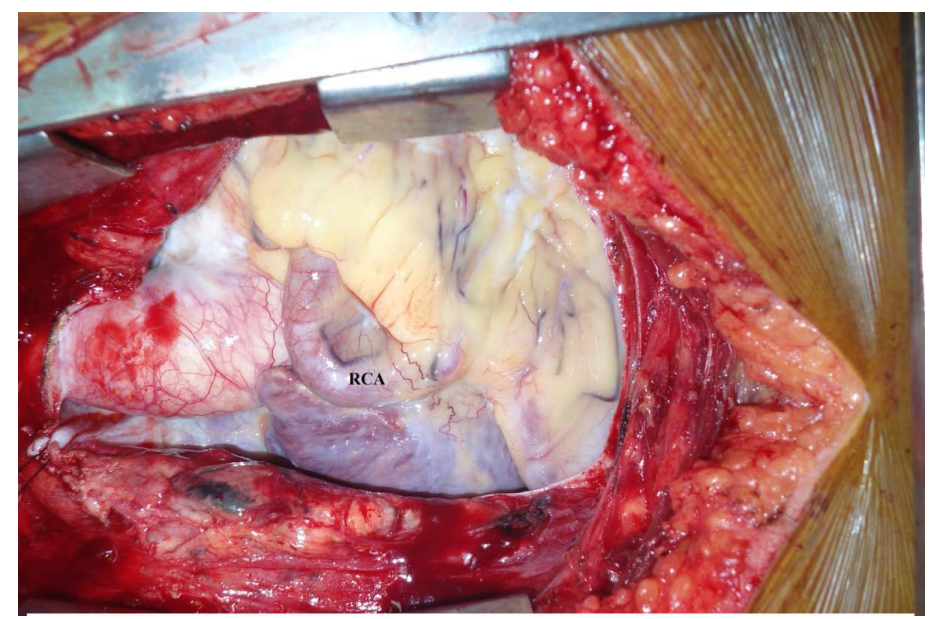

Figure 4. Showing tortuous right coronary artery running along atioventricular groove.

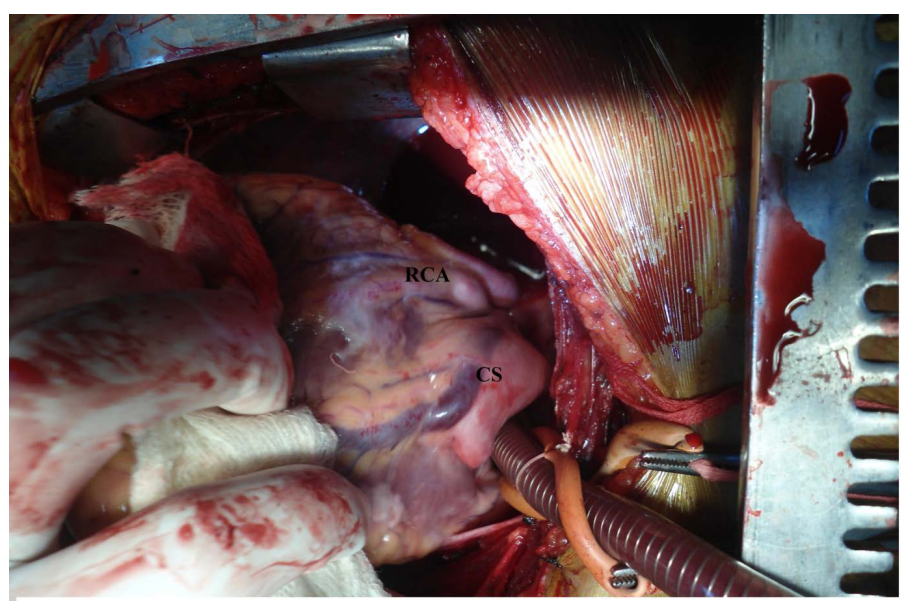

Figure 5. Showing dilated coronary sinus and dilated tortuous RCA running along inferior wall of left ventricle.

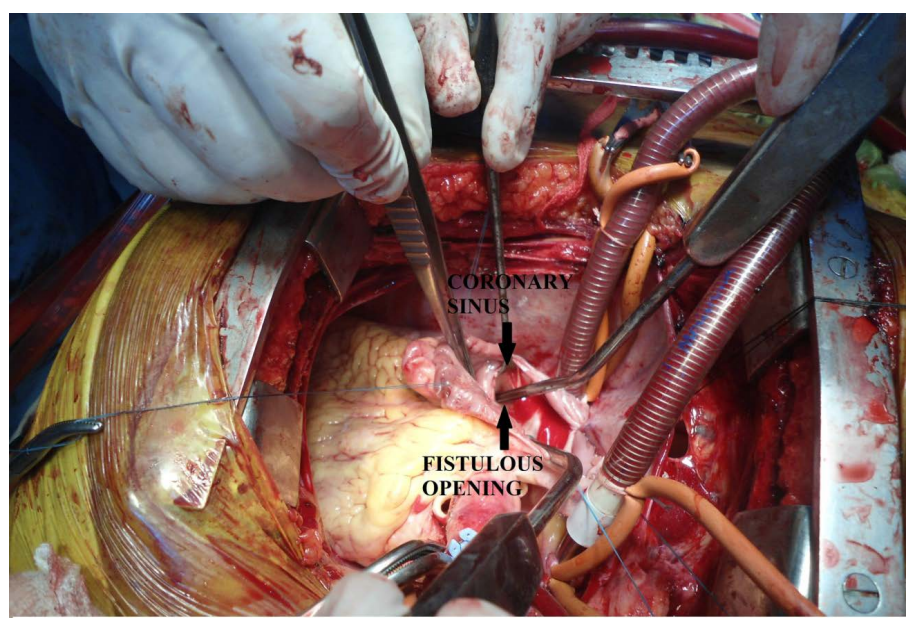

Figure 6. Showing opening of fistula into coronary sinus. Tip of sucker passing through fistulous opening. 


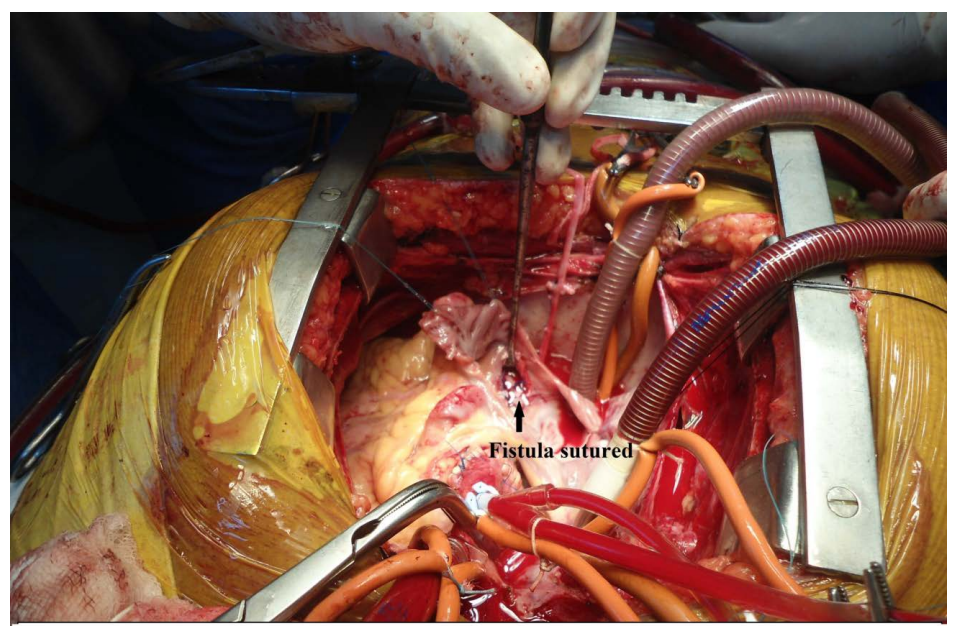

Figure 7. Showing suture closure of fistulous opening.

aorta following which patient was successfully weaned off bypass. Post-operative period was asymptomatic and patient was discharged on $7^{\text {th }}$ post-operative day. After three years of follow up patient is asymptomatic with a patent graft (Figure 8).

\section{Discussion}

Coronary arteriovenous fistula is a direct communication of one or more coronary arteries with a cardiac chamber or great vessel bypassing the myocardial capillary bed. This is a rare congenital anomaly presenting in or after second decade of life with symptoms and complications of excessive left to right shunt or as an incidental finding in association with valvular or coronary artery disease.

About 10,340 coronary angiograms were reviewed by Davidavicius and colleagues [1], where they identified coronary artery anomalies in $1.8 \%$ of the cases. Coronary artery fistulas can communicate with any cardiac chamber [2] [3] [4], the RCA being more frequently involved (55\%) [4]. Most frequently it drains into the right ventricle, right atrium, and pulmonary veins [2], whereas drainage to the coronary sinus occurs least frequently [5].

Coronary arteriovenous fistulas are usually asymptomatic during first two decades of life, especially when they are haemodynamically small. Symptoms depend on size of the fistula, degree of shunting and associated complications. The left to right shunt can lead to volume overload and heart failure. Potential complications include steal from myocardium causing myocardial ischemia, thrombosis and embolism, endocarditis, arrhythmia, rupture and sudden death [6] [7] [8] [9]. There has also been a reported evidence of spontaneous rupture of aneurysmal fistula leading haemopericardium [10].

Due to the potential complications, it is generally recommended to close the fistulous communication either surgically or by transcatheter approach when diagnosed. 


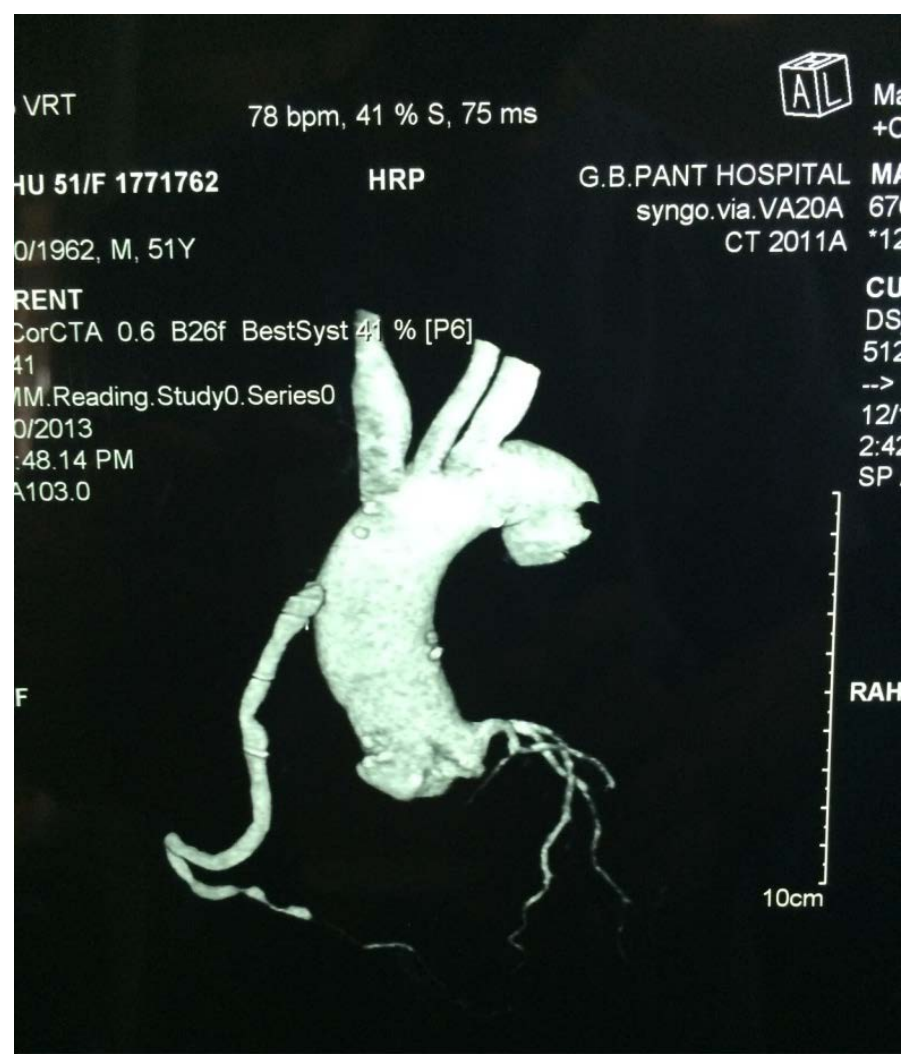

Figure 8. Post-operative CT angiography after one year follow op showing patent graft.

Patients with unsuitable anatomy like extreme vessel tortuosity, multiple drainage sites, coronary artery branching at the site of device positioning and with other associated complex heart disease amenable for surgery are not feasible for transcatheter closure [11].

The aim of the surgery is to close the fistulous communication and thus, obliterating the left to right shunt along with preservation of myocardial perfusion. Wauthy and colleagues [4] reported the successful ligation of a smaller fistula in a younger patient. Our case was a right coronary artery to coronary sinus fistula with an aneurismal dilatation of RCA, with a late presentation in sixth decade of life with angina and impending failure. Although the clinical features did not conclude any diagnosis but computed tomography and conventional angiography confirmed the diagnosis. Leaving behind the intact large tortuous segment of coronary vessel could have induced thromboembolism. This is why we obliterated the proximal ostial opening of RCA, resected the proximal aneurismal vessel and did an interposition bypass grafting with $8 \mathrm{~mm}$ Dacron graft from ascending aorta to mid RCA to avoid thromboembolism and myocardial ischemia. Patient is under regular follow up since last 3 years and is asymptomatic. Therefore early detection and urgent surgical management has a good prognostic value before complications sets in. 


\section{Conclusions}

A coronary arteriovenous fistula presenting late with symptoms of angina and congestive heart failure demands urgent surgical intervention. Resection of aneurismal coronary artery and division of fistulous tract at the coronary sinus with a bypass grafting from ascending aorta to distal RCA is the basis of management.

We conclude that in a coronary artery aneurysm with a coronary sinus fistula, the surgery should be precisely planned and emergently taken up. Myocardial protection during cardioplegic infusion should be ascertained; the fistulous opening must be identified and sealed thoroughly. Resection of the aneurismal coronary artery with a proper revascularisation of the hypertrophied myocardium is of paramount importance.

\section{References}

[1] Davidavicius, G., Šubkovas, E., Abraitis, V., Zabukas, A., Beniušis, V., Jerdiakovas, M., Bilkis, V. and Kibarskis, A. (2004) Coronary Anomalies: Single Centre Experience. Seminars in Cardiology, 10, 208-213.

[2] Lowe, J.E., Oldham Jr., H.N. and Sabiston Jr., D.C. (1981) Surgical Management of Congenital Coronary Artery Fistulas. Annals of Surgery, 194, 373-380. https://doi.org/10.1097/00000658-198110000-00001

[3] Habermann, J., Howard, M. and Johnson, E. (1962) Rupture of the Coronary Sinus with Hemopericardium. A Rare Complication of Coronary Arteriovenoufistula. Circulation, 18, 1143-1144.

[4] Wauthy, P., Demanet, H. and Deuvaert, E. (2003) Surgical Treatment of Coronary Artery Fistula with Aneurysm. Acta Chirurgica Belgica, 103, 532-533. https://doi.org/10.1080/00015458.2003.11679485

[5] Ieva, R., Correale, M., De Luca, G. and Di Biase, M. (2007) A Coronary Artery Fistula with Aneurysm Draining into the Coronary Sinus: Role of Transesophageal Echocardiography. American Journal of Geriatric Cardiology, 16, 112-114. https://doi.org/10.1111/j.1076-7460.2007.05208.x

[6] Wilde, P. and Watt, I. (1980) Congenital Coronary Artery Fistulae: Six New Cases with a Collective Review. Clinical Radiology, 31, 301-311. https://doi.org/10.1016/S0009-9260(80)80223-6

[7] McNamara, J.J. and Gross, R.E. (1969) Congenital Coronary Artery Fistula. Surgery, 65, 59-69.

[8] Alkhulaifi, A.M., Horner, S.M., Pugsley, W.B. and Swanton, R.H. (1995) Coronary Artery Fistulas Presenting with Bacterial Endocarditis. Annals of Thoracic Surgery, 60, 202-204. https://doi.org/10.1016/S0003-4975(95)00037-2

[9] Skimming, J.W. and Walls, J.T. (1993) Congenital Coronary Artery Fistula Suggesting a "Steal Phenomenon" in a Neonate. Pediatric Cardiology, 14, 174-175. https://doi.org/10.1007/BF00795649

[10] Bauer, H.H., Allmendinger, P.D., Flaherty, J., Owlia, D., Rossi, M.A. and Chen, C. (1996) Congenital Coronary Arteriovenous Fistula: Spontaneous Rupture and Cardiac Tamponade. Annals of Thoracic Surgery, 62, 1521-1523. https://doi.org/10.1016/0003-4975(96)00757-6 
[11] Armsby, L.R., Keane, J.F., Sherwood, M.C., Forbess, J.M., Perry, S.B. and Lock, J.E. (2002) Management of Coronary Artery Fistulae. Patient Selection and Results of Transcatheter Closure. Journal of the American College of Cardiology, 39, 10261032. https://doi.org/10.1016/S0735-1097(02)01742-4

Submit or recommend next manuscript to SCIRP and we will provide best service for you:

Accepting pre-submission inquiries through Email, Facebook, LinkedIn, Twitter, etc.

A wide selection of journals (inclusive of 9 subjects, more than 200 journals)

Providing 24-hour high-quality service

User-friendly online submission system

Fair and swift peer-review system

Efficient typesetting and proofreading procedure

Display of the result of downloads and visits, as well as the number of cited articles

Maximum dissemination of your research work

Submit your manuscript at: http://papersubmission.scirp.org/

Or contact wjcs@scirp.org 